JEL Classification: M37; M31; Z33.

DOI: 10.46361/2449-2604.7.2.2020.18-25

3эms asaymsdo

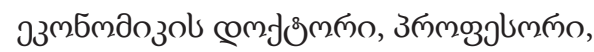

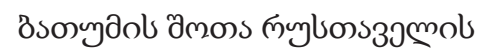

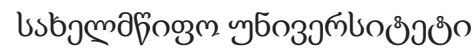

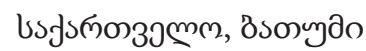

Mamuladze.gela@bsu.edu.ge orcid.org/0000-0001-8651-3808

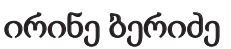

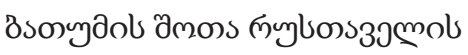

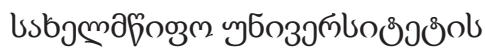

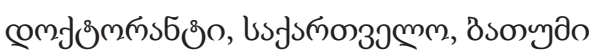
irina.beridze@bsu.edu.ge orcid.org/0000-0001-5645-8633

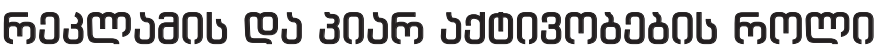

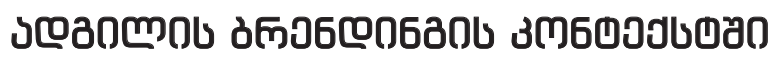

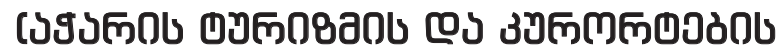

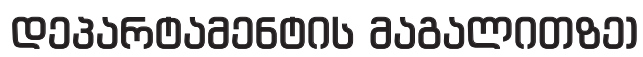

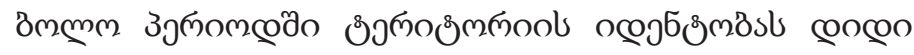

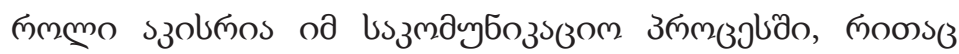

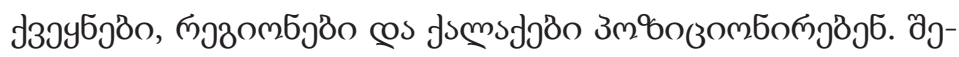

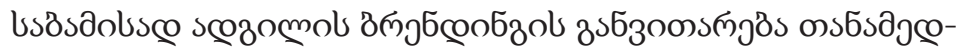

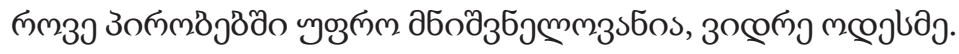

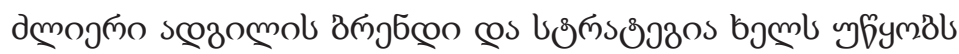

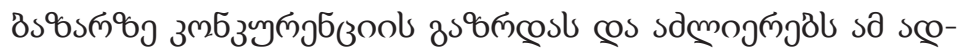

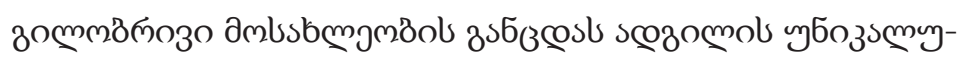

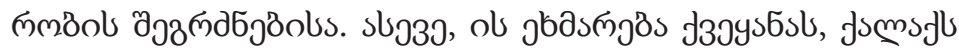

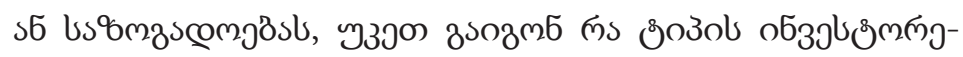

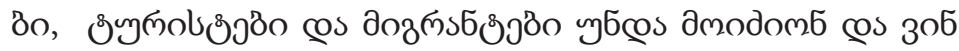

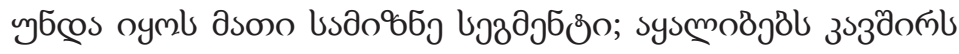

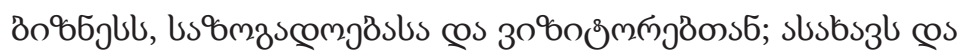

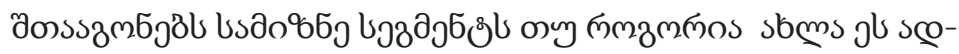

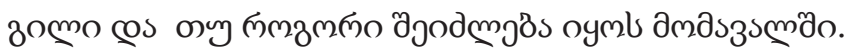

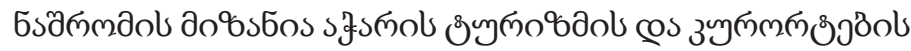

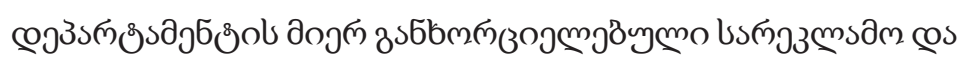

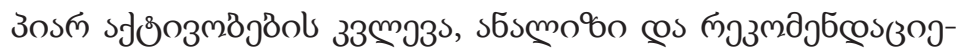

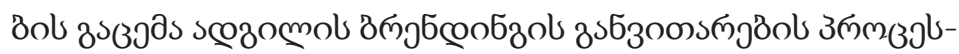

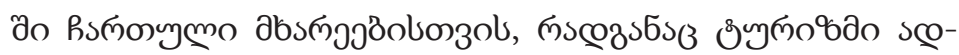

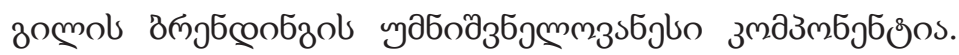

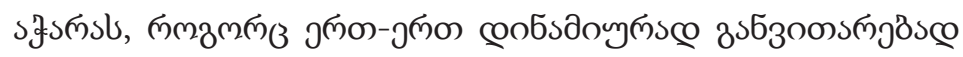

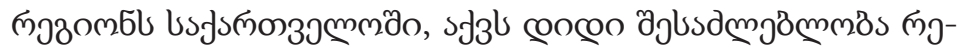

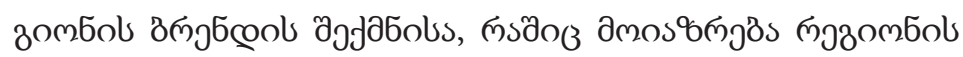

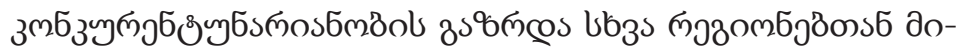

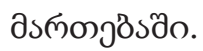

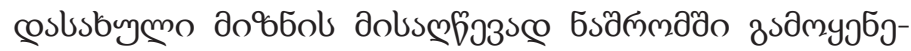

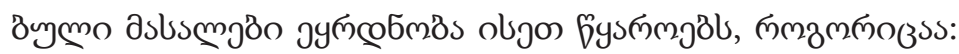
Google Scholar, Scopus, WOS (Web Of Science) @os s.d. sbo3つ

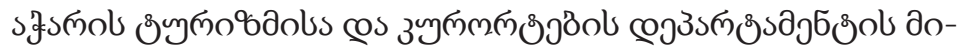

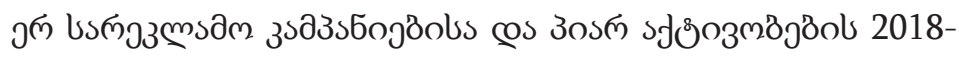

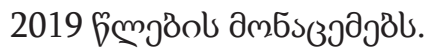

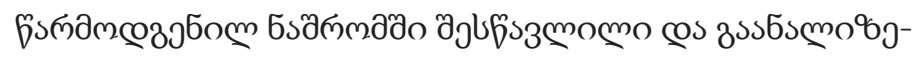

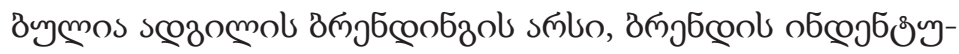

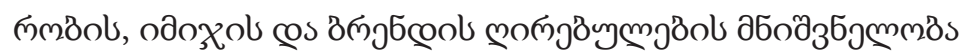




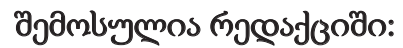

o36olo, 2020

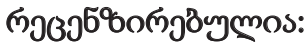

o3molo, 2020

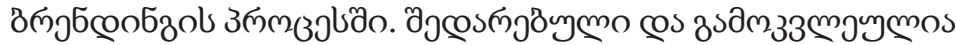

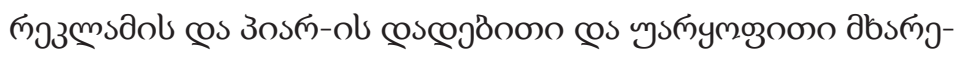

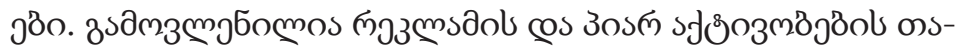

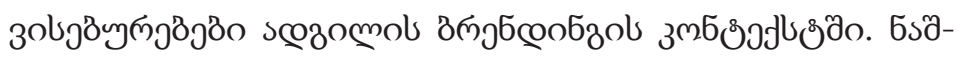

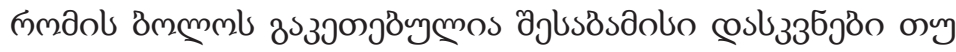

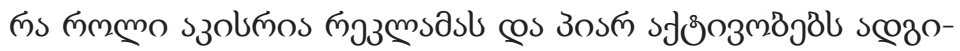

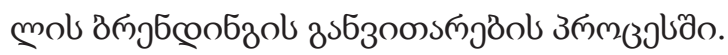

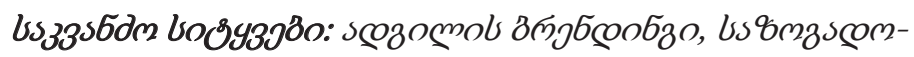

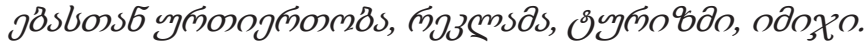


JEL Classification: M37; M31; Z33.

DOI: 10.46361/2449-2604.7.2.2020.18-25

\section{GELA MAMULADZE}

Doctor of Economics, Professor

Batumi Shota Rustaveli State University

Georgia, Batumi

Mamuladze.gela@bsu.edu.ge

orcid.org/0000-0001-8651-3808

\section{IRINE BERIDZE}

PHD Student of Batumi Shota

Rustaveli State University

Batumi, Georgia

irina.beridze@bsu.edu.ge

orcid.org/0000-0001-5645-8633

Edited by:

June, 2020

Reviewed by:

July, 2020
(C) Innovative Economics and Management, 2020

\section{THE ROLE OF ADVERTISING AND PR ACTIVITIES IN PLACE BRANDING CONTEXT [IN THE CASE OF THE DEPARTMENT OF TOURISM AND RESORTS OF AJARAJ}

In recent years, territorial identity has played a major role in the communication process by which countries, regions and cities are positioned. Consequently, in modern times development of place branding is more important than ever. A strong place brand and strategy help to increase competition in the market and enhance experience of local population to feel uniqueness of this place. It also helps a country, a city or a community to understand better what type of investors, tourists and migrants to look for and who should be their target segment, builds relationship with business, community and visitors, reflects and inspires the target segment what is this place now and what might be in the future.

The purpose of the work is to research, analyze PR activities and advertising campaigns carried out by the Department of Tourism and Resorts of Ajara and issue recommendations for the stakeholders those are involved in the development process of place branding as tourism is one of the significant component of place branding. Ajara, one of the dynamically developing regions in Georgia, has great opportunity to create a place brand that means to increase competitiveness of the region in relation to other regions.

In order to achieve the goal, the paper covers literature analyses from sources such as Google Scholar, Scopus, WOS (Web Of Sci-ence) etc. and the data of advertising campaigns and PR activities by the Department of Tourism and Resorts of Ajara in 2018-2019.

Essence of place branding, brand identity, brand image and brand equity were studied and analyzed in the presented work; pros and cons of advertising and PR were studied and compared as well. There were identified peculiarities of advertising and PR activities in place branding context. Relevant conclusions were made about the role of advertising and PR activities in place brand developing process.

Key words: place branding, public relations, advertising campaign, tourism, image 


\section{Introduction}

In order to answer the questions why should we live in a particular place? Why should we visit this or that place? Why invest? And simply why should we say that this country has the values we can achieve our aim here right now and future, we studied an important topic - place branding.

Place branding is a set of place-based elements that range in scope from logos and slogans (Anholt, 2005; Braun, Eshuis, and klijn, 2014; Cleave and Arku, 2015; Zenker 2009) to a broader range of place attributes including promotional and marketing, expressions of place through the built and natural environments, actions and attitudes of local and key stakeholders, and quality of local infrastructure (Hall and Hubbard, 1996; Kavaratzis, 2005).

Place branding applies for creating image and desire to create positive associations with the place and it focuses on image and reputation. According to place branding process the place must be represented from the values it has, transferred these values to export, raise awareness and be positioned properly.

In an age of advanced technology and information, it is essential to send an accurate and timely message to the customer in a timely manner. Places need to be prepared to manage their own image with appropriate channels and appropriate manners. "Brand image" is the set of beliefs or associations relating to that name or sign in the mind of the consumer" Simon Anholt (2010). As the aim of the paper was to analyze the role of advertising and PR activities in the case of the Department of Tourism and Resorts of Ajara, we considered the topic important to be studied.

According to the tourism branding strategy of Ajara (noteworthy is the fact that place branding and place marketing are different from each other), the region is positioned as coastal, cozy, mountainous place which offers adventures and atmosphere full of emotions. It is a mix of old and new, interesting with its culture, history, sunny and rainy weather and hospitable people. As it is mentioned above, in order to develop a place brand it needs "A robust and productive coalition between government, business, civil society, as well as creation of new institutions and structures to maintain competitive identity" - Simon Anholt (2008).

The Department of Tourism and Resorts of Ajara, as one of the important stakeholder (component) of the region place branding uses tools of integrated marketing - PR and advertising in order to enhance place image associations, increase awareness and promote the place which is showed by its activities carried out for last 2 (2018-2019) years. The Department promoted the region in more than 16 target countries through TV channels - CNN, BBC, Euronews, Doutche Welle, National Geographic, Travel Channe, RTL; applied for out-of-home advertisings, online and social platforms; participated in tourism exhibitions and held press tours.

\section{Literature Review}

The conceptual boundaries and prospects of place branding were a new challenge in the late nineties and early twentieth. The origin of the term branding and evolution of the theory are related to the names of postmodern English scientists such as Simon Anholt, Dean and Olin. The concept of country branding is an important part of multidisciplinary and interdisciplinary scientific research, sometimes referred to as thematic, regional, geographical, geo-brands, nations or place branding.

In 2002 (according to some data in 1996), a branding specialist, Simon Anholt was the first to use a term "place branding" and then developed a diversified, complex approach to area branding 
that contrasted with previously narrow specialized approaches (which focused on only one aspect of area branding, such as tourism). But up to date no one can agree on exactly what place branding means. According to some authors: "A place brand is a network of associations in the place consumers' mind based on the visual, verbal and behavioral expression of a place and its' stakeholders. These associations differ in their influence within the network and in importance for the place consumers' attitude and behavior" (Zenker, S. and Braun, E. 2017); "Place branding (includes place marketing and place promotion) is a term based on the idea that "cities and regions can be branded," whereby branding techniques and other marketing strategies are applied to "the economic, political and cultural development of cities, regions and countries." (Kemp, Elyria; Childers, Carla Y.; Williams, Kim H. 2012); "As opposed to the branding of products and services, place branding is more multidimensional in nature, as a 'place' is inherently "anchored into a history, a culture, an ecosystem (Kapferer, Jean- Noël. 2013). As well as, Greek professor Kavaratzis (2010) emphasizes the notion that place branding is different from place marketing.

It turned out to be a very interesting and innovative statement in the history of branding when Simon Anholt compiled the Country Brand Index in 2006, which was defined by six parameters: export, investments, quality of public administration, people, culture and tourism that measure global perceptions of countries and it has lasted up to now to rank the countries according to this index.

Later, Robert Govers, Erik van 't Klooster and Gerard Van keken formed a set of place branding principles to guide the brand development and management, which encompasses place distinctiveness, authenticity, memorable, co-creation and place-making.
Branding process involves designing, planning and communicating between the name and identity in process of building reputation and brand which is based on four elements: brand identity, brand image, brand objective and brand equity (Anholt, 2007). Robert Govers, Erik van 't Klooster and Gerard Van keken, (2015) consider that sustainable competitive advantage can be created by building brand equity in relation to the identity of the nation, region, local area or city or town.

It should be also noted that the brand of the place has been considered as the brand equity since 2000 (Keller 1993, 1998) and is used as a measure of the place's brand performance. Professor Kavaratzis, considers brand identity as a measure of brand performance as well.

As place branding specialists Morgan and Fritchard (1999) point out, the brand of a place must have unique identity that allows the customer to distinguish it from others. Dean (2008) believes that the development of brand identity should be more involved, even in ideological associations such as country's political and economic stability.

As for the place brand image, they can be differed as a real and future (planned) image of the place. Advertising and PR campaigns are mainly carried out within the framework of the real image of the region, or the place is always exposed, showing what is unique about the place /peculiarities of the place, no matter how humiliating or modest. In the case of planned place image, it is considered the vision of the future of the place which is not real yet.

As brands are built with publicity and maintained with advertising ( $\mathrm{Al}$ and Laura Ries 2002). One of the first aim of advertising is to inform, to persuade and to remind. Informative advertising creates awareness of brands, products, services, and ideas. It is paid 
and promotes through different types of media including online, TV, out-of-home advertising, radio etc.

According to Gyorgy Szondi (2010) PR' s role in place branding - there are many ways of applying for PR to build and maintain relationships with stakeholders in the place branding context. PR can contextualize the place branding initiative and create a favorable environment for the overall branding project, which must be carefully prepared.

Public relations are generally associated with communication activities considered to master and preserve brand's image and relationship with its public. "Clients are looking for integrated programs and consistent brand messaging across every point of contact with their customers" (Baruzzi, 2010). "Public relations don't just focus on your business product; it also assists in shaping strategic messaging" (Benyman, 2010).

There is a range of differences between advertising and $P R$. As advertising is paid while $P R$ develops tactics to gain positive media attention which is very affective at increasing your target audience's brand awareness; advertising content is controlled by you where and when it will be seen in the media that is not easy in case of PR; coverage duration for advertising depends as the budget allows, but in case of PR the story can be published in different ways, which may be more effective at reinforcing the message; $\mathrm{PR}$ is more credible/believable than advertising for the target audience.

On bases of most place brand specialists, in spite of PR and advertising are essential aspects in place branding process, they do not lead the way into brand building.

Purpose and Results

The purpose of the paper was to analyze advertising campaigns and PR activities in place branding context, in the case of the Department of Tourism and Resorts of Ajara, as it is one of the significant stakeholder (component) of the process. How advertising campaigns and PR activities have supported to increase awareness, to develop proper associations of the region in place branding context, we have studied advertising campaigns and PR activities of the Department of Tourism and Resorts of Ajara for 2018-2019.

The Department of Tourism and Resorts of Ajara, as one of the important stakeholder in place branding has used various marketing tools: Commercials on international TV channels, social networks, out-of-home advertising, press tours and exhibitions.

According to the official statistics for 20182019 of the Department of Tourism and Resorts of Ajara, after carried out advertising campaigns and PR activities, place (Ajara) awareness was increased, which in turn increased a number of tourists in the region.

In 2018 The Department of Tourism and Resorts of Ajara promoted the region more than in 16 target countries though different marketing tools including TV commercials on BBC, Euronews, Deutche Welle, RTL, NTV. As well as out-of-home advertising in more than in 35 target cities and advertising for online and social platforms in 14 countries.

Advertising articles about Ajara were published in the leading airline magazines and popular media publications in the target countries: Wizzair Magazine, Qatar Airways, British Airways, Ukraine International Airlines, Scat Airlines, Where.ge, Travel Poland, Nat Geo Traveller, Business Treveller, Birdwatch.

Online advertising more than in 15 target countries (Armenia, Azerbaijan, Russia, Ukraine, Belarus, Poland, Germany, Latvia, Lithuania, Estonia, The United Kingdom, Israel, Kazakhstan, Saudi Arabia, UAE) through the following 
platforms: Facebook, Instagram, Google Display

Network, Google Search, YouTube.

Within the country, the region was promoted by out-of-home advertising, videos in the cinema, articles in the Georgian railway magazine, advertising on Georgian radios and active online campaigns.

Videos for the region and seasons, ski resorts (Gomarduli, Goderdzi), rural tourism were also made in 2018.

As for exhibitions, press tours, mobile applications in 2018, exhibitions - the region was presented in 24 international tourism exhibitions around the world including London, Madrid, Frankfurt, Telaviv, Tallinn, Vilnius etc. Press tours - 125 journalists and 110 tourist agency's representatives visited Ajara. 18 press tours were organized from Estonia, Poland, Belarus, Israel, Turkmenistan and Sweden. A mobile app. was created for the region on Android and IOS platforms.

With reference to data for 2019, touristic products were introduced to $\mathrm{BBC}$, Deutche Welle, Euronews, National Geographic and Travel Channel viewers. Videos on Ajara were aired on international TV channels for a month.

In addition to TV commercials, the region was promoted in 16 target countries through various marketing tools: advertising articles about region were published in the leading airline magazines of Turkish airlines, Belavia, Wizzair, Ukrainian Airlines and Scat; The trams in Riga and Tallinn were branded by the photos of Ajara; Online advertising were in 14 target countries except Russia and Turkey on Facebook, Youtube, Instagram, Google Search and Google Display Network; Press tours were held from the neighboring countries.

As a result, after estimating of carried-out activities by the Department of Tourism and Resorts of Ajara, the region is positioned as an exceptionally open, free and hospitable place and evokes the proper associations. On the other hand, the region awareness has been increased; interest of eco-tourism has been expressed. As well as, infrastructure adjustment of the region authenticity has become a priority for the regional government. That will support to implement region's future image as a four season tourist destination. Highly rated channels as Travel Channel, National Geographic, Xpedia were interested to cover the region.

Tourism is one of the important components in place branding. Thus, its sustainable development will be benefit for Ajara-place branding process.

\section{Conclusion}

Based on the study and analysis of above mentioned materials, our work has led us to draw the following conclusions:

$>$ Advertising campaigns and PR are solid marketing tools and are critical aspects in place branding in order to promote the place but they do not lead the way into brand building. That is why it is advisable to balance it with development of brand strategy.

> Advertisng and PR activities carried out by the Department of Tourism and Resorts of Ajara last years, as it is confirmed by the official statistics, increased the region awareness, which in turn increased the number of foreign tourists. In spite of this result, it can not create a brand image, reputation and then manage it in the context of place branding, because place branding is not about communications, it is about policies. Therefore, the priority of region's government should be to create and develop a unified concept of place branding not only in marketing but also in strategic direction. 
In accordance with the conducted research, it is clear that good advertising and PR campaigns achieve its goals, but today it has not been proven that by using of marketing communications is possible to influence on person's perception of an entire city, region or country. It is recommended to be involved all of place branding stakeholdersgovernment, local population, business representative, visitors in place branding process and altogether continue working on developing place branding strategy and a tourism brand strategy itself as it is one of the significant component of place branding.
On bases of researched material, we can conclude that it is not a right approach that marketing campaigns are able to open or close a "box of perceptions", when all of this is focused on place branding, in such case we can only add associations or direct them to the desirable course. While working on this issue, it should be focused on a proper state of natural environment (location, scenery, weather, climate); built environment (city/ town, infrastructure, amenities, lodging and accommodation, entertainment); culture and heritage (historic sites, art, heritage, events); people (lifestyle behavior, values, interaction with visitors).

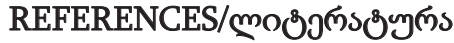

[1] Zenker S., Braun E., «Questioning a "one size fits all" city brand: Developing a branded house strategy for place brand management", Journal Place Management and Development. 2017.

[2] Kavaratzis M., Hankinson Warnaby G., Ashworth G. Rethinking of Place Branding. 2015.

[3] Anholt S., "Competitive Identity. The New Brand Management for Cities and Regions", Pallgrave Macmillan. 2007.

[4] Anholt S., Place Brandin and Public Policy. 2017.

[5] Simon., Strategic branding of destinations: a framework. Emerald Group. 2009.

[6] Govers R. Frank G. Place Branding: local, Virtual and Physical Identities. Constructed, Imagined and Experienced. 2009.

[7] Aitken R., Cambelo. The Four Rs of Place Branding. Journal of Marketing Management. 2011.

[8] Dinnie K., National Branding: Concepts, Issues, Practice. Oxford. 2008.

[9] Ashworth G.J.; Kvaratzis M., Warnaby G., Beoyened Th Logo Brand Mangamnet for Cities, Journal of Brand Managament. 2009.

[10] http://gobatumi.com/en/home

[11] https://link.springer.com/article/10.1057/palgrave.pb.6000088)

[12] https://placebrandobserver.com/5-place-branding-principles-to-guide-brand-development-management/ 